\title{
XXV. On single and double vision produced by viewing objects with both eyes; and on an optical illusion with regard to the distance of objects
}

\author{
John Locke
}

To cite this article: John Locke (1849) XXV. On single and double vision produced by viewing objects with both eyes; and on an optical illusion with regard to the distance of objects, Philosophical Magazine Series 3, 34:228, 195-201, DOI: 10.1080/14786444908646207

To link to this article: http://dx.doi.org/10.1080/14786444908646207

冓 Published online: 30 Apr 2009.

Submit your article to this journal $[\pi$

ЏII Article views: 2

Q View related articles $₫$ 


\section{$\left[\begin{array}{ll}195 & ]\end{array}\right.$}

XXV. On Single and Double Vision produced by vieving objects with both eyes; and on an Optical Illusion with regard to the distance of objects. By JoH N Locke*.

THAD commenced the investigation of this subject so early 1 as 1816, while I was a student of medicine in Yale College, and I have occasionally turned my attention to it up to the present time.

Although I have been fairly anticipated in the publication of some of my results, perhaps most of them, by the late investigations of Prof. Wheatstone + and $\mathrm{Sir}$ David Brewster $\neq$, yet 1 deem it not useless to give you an account of the history of my own experiments and conclusions, especially as some of them are not, so far as I know, contained in the publications of either of the distinguished philosophers who have just written upon the subject. It is a well-known phænomenon, that with both eyes open we can see a single object either single or double, according as the axes of the eyes are made to converge and meet either at the object, or at a point nearer than that object. Having acquired the powei of voluntary convergence of the optical axes to an extreme degree without the aid of viewing near objects, such as the nose, or a finger held near to the eyes, I commenced my experiments as follows :-

Experiment I. - I viewed a burning candle at the distance of about eight feet, the axes of the eyes being "crossed" or extremely converged. Two images were of course' seen, the distance between which could be varied at pleasure by the amount of that convergence. The two images of the candle being thus seen, I suddenly closed one of my eyes, when the image on the same side of the closed eye vanished. Thus on closing the right eye, the right image disappeared; and on closing the left eye, the left image became extinct.

Inferences. - 1 st. As the axis of the right eye was directed to the left of the object, and the image which disappeared on closing that eye was to the right of it, that image must have been an oblique one, seen as we see lateral objects to which the eyes are not directed. It appears, too, that while the axes were converged upon vacancy, the oblique image in the right eye took the place of an image formed directly in the axis of the left eye, and the same relatively of the left eye; thus each eye appeared to have an image in its axis, which image was really in the opposite eye $\$$.

* From Silliman's Journal for January 1849.

+ I have not seen bis paper.

+ Phil. Mag., May 1847.

$\$$ This is not always the condition of strabismus, for one eye may be so directed that the axis shall be on the object while the other is oblique.

O 2 
2nd. The two oblique images on the retina must have been formed on points nearer to the nose, or nearer to the medial line of the body than the principal axis of perfect vision.

3rd. The images appeared in such position as objects should have been to produce pictures on the same parts of the retina, the axes being at the same time parallel, or nearly so.

4th. As with both eyes we see a lateral object ordinarily single, especially when at the same distance as the principal object viewed, it is inferred that the two pictures, one in each eye, must fall on parts of the retina not correspondent to the medial line of the body in order to produce single vision. For example, on looking at a person standing ten yards in front, the image of a person standing two yards or more to the right will appear single though not well-defined. The picture of this second person must in such case be formed to the left side of the retina of both eyes, towards the nose in the right eye, and from it in the left eye. In these two situations on the retina, and in no other, will the two oblique pictures present a single image to the mind.

5th. All this establishes the principle, that certain parts of the retina of one eye CORRESPON $\mathrm{D}$ to certain specific parts of the retina of the other eye, in such a manner that when identical pictures fall on those corresponding parts, single vision is the vesull. Those corresponding parts lie inward in one eye and outward in the other, viz. both to the right or both to the left. From each of those corresponding parts of the retina it is probable that the fibres of the optic nerve proceed, and severally unite at the point of anatomical communication where the optic nerves cross before entering the brain; hence the single impression or single image.

It may be added to this experiment (I.), that if the fingerbe pushed against the under part of the eyeball so as to roll it upward, the image in that eye will appear to descend, and double vision will thus be the result. Here the eye being rolled upward, the image falls on the upper part of the retina; hence the impression of a lower object would form a picture on that part, were the eye not distorted*.

Experiment II.-Two candles of equal size and height were placed side by side on the table, and by converging the axes of the eyes, four images were produced. As the convergence progressed, each pair of images receded gradually from the original place of the single image until the two contiguous ones, the second and third, approached, and finally coalesced

* In all cases the mind seems to make no allowance for distortion of the eye, but refers the image to its true place were the eye in its natural position. 
into one, when three images only were in view. 'The same experiment may be made with two letter's, or any other figures or objects which are equal in size and form, as follows:-
1. A A Natural single vision.
2. AA AA View with axes slightly converged.
3. A A $\{$ View with greater convergence of the op- 3. A A A $\left\{\begin{array}{l}\text { tical axes and the two intermediate } \\ \text { images coalesced into one. }\end{array}\right.$

On suddenly closing either eye, this middle or superimposed image did not disappear, and it was evidently made of two images from two objects formed on corresponding parts of the retina. Hence we have the converse of the case of double vision of a single object, for two objects are made to produce a single impression. Thus far I had proceeded in 1816, when I read a paper on this subject to a club of my fellow-students at Yale.

Experiment III.-In 1843 I made the experiment of converging the optical axes upon two contiguons figures on the wall-paper of my office, in the same manner as I had done with the two images of the two candles in Exp. II. When I had thus succeeded in taking up optically the two figures and superimposing them one upon the other, suddenly the whole wall appeared to leap out from a distance of ten feet to within half a yard of my eyes, where it remained in miniature beauty as palpable to vision as it had been in its original place. 'To this inage, suspended as it were between the observer and the object, I shall in the subsequent part of my paper apply the term illusive image.

It then appeared that the right eye was directed to the left one of two contiguous figures, and the left eye to the right figure, which, being identical in form and size, gave the impression of a single object at the point of intersection of the optical axes. Here we have two triangles formed by the two optical axes intersecting each other and joined at their extremes; on one part by a line from one eye to the other, and on the other part by a line from one figure or object to the other. These last lines being parallel (see figure), where $A$ and $B$ represent the eyes, $C$ and $D$ the objects, or two figures on the wall, $A D$ the axis of the eye $A, B C$ the axis of the eye $B$, and $E$ the point of intersection of the axes at the place of the illusive image. As these triangles are equiangular and similar, we can deduce from them all of the equations of such triangles and apply them to the optical pha-

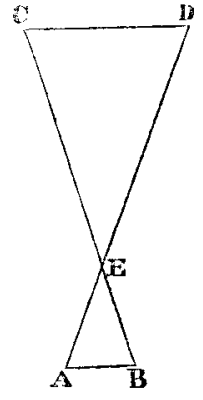


nomena. Thus the distance from the eye to the illusive image (AE) will be to the distance from the object to the same image (DE) as the distance between the eyes (AB) is to the distance between the objects (CD) the figures or pannels on the paper, \&c.

It is not merely the two objects directly in the axes of the eyes which coincide, but every contiguons pair of objects seen obliquely will also coincide, and form the illusive picture in extenso. Indeed the optical operation of convergence seems like taking up a duplicate copy of the figures lying in the first place exactly over them, and slipping it gradually to the extent of one figure, until again the figures coincide in a new place.

Some of the phanomena of the Illusive Image.-It is quite perfect, and can be viewed deliberately and critically as if it were a real substance in place as it appears; the figures are smaller than the originals in proportion as they are nearer; as the outlines are a little blended by double pictures not exactly coincident, an elegant softening and a playful beauty exalts their effect above that of the original; as the head moves sideways, upward or downward, the illusive image moves, but with a diminished motion; as the head is inclined to the right or left, the superimposed pictures slide out from each other, the one ascending and the other descending to the extent of the inclination.

Optical Equivalency.-The illusive image and the erroneous distance at which it appears, show evidently that philosophically we do not see an object, but we contemplate an image on the retina. If this image can by any means be formed without the object, we still contemplate the substance such as would .produce that image. Thus in Exp. III., and the figure illustrating that experiment, the two objects $\mathrm{C}$ and $\mathrm{D}$ produce each picture in the eyes at $A$ and $B$, exactly as would be produced by a single object of smaller size at $\mathrm{E}$. Thus the two objects, one at $\mathrm{C}$ and the other at $\mathrm{D}$, "fulfill the conditions of the problem" of the images on the retina, exactly as it would be fulfilled by a single smaller object at $\mathrm{E}$. In both cases identical pictures are formed on "corresponding" parts of the two retinæ. Hence the two objects produce the impression of a single image.

Directions how to make the experiment of the Illusive Image. -With two identical objects only, although it is easy to superimpose them as in Exp. II., yet the illusion of distance can scarcely be attained. But with a papered wall having a repetition of the same figure at equal distances, a person who has voluntary command of the optical axes will soon move the double images to coincide, when presently the illusion will be 
perfect. Persons who have not this command of their eyes may succeed in obtaining the proper convergence by looking at a finger held about fifteen inches from the face, while standing ten feet from a wall with figures twenty inches apart.

Apparent distances of objects.-It seems that we judge of moderate distances by a kind of triangulation, the distance between the eyes being a constant base-line. In order to put this to the test, I have several times made the actual measurements as in the following cases:-

Having measured the distance between my eyes, $2 \cdot 6$ inches, the distance between the figures on the wall 21 inches, the distance from the wall 10 feet, the distance of the illusive image was calculated to be 14.7 inches, when it had been measured as near as may be 14.5 inches. In a second experiment we endeavoured to ascertain the distance of the observer from the wall. The other data were-

Distance between the eyes . . $2 \cdot 6$ inches.

Distance between the figures . 21 inches.

Distance of illusive image . . 16.75 inches.

Calculated distance of the wall .12 .5 feet.

Measured distance of wall . 13.15 feet.

When it is recollected that the observer is obliged to range lengthwise on his measure while he determines the distance of the aërial image, and that the base-line is only 2.6 inches, the above results appear quite as accurate as we ought to anticipate.

There is peculiar beauty and accuracy in some of the results of these experiments ; and it had occurred both to Sir David Brewster and myself, that when a strip of wall-paper was placed at a greater or less distance from its fellow than others, the illusive image would not appear in the same place, some strips would advance a little and others would recede, so as to fulfill the conditions of the triangles above named; even the sixteenth of an inch would be appreciable.

In the history of my examination of this subject, I would observe that my friend Dr. D. S. C. H. Smith, of Sutton, was present when my paper was read at New Haven. In 1845, my assistant, Thomas K. Beecher, A.M., witnessed and repented most of the experiments above named. Among other things we made the equations dependent upon the above triangles, and verified our calculations by actual admeasurement of the distances between the eyes, between the objects, and to the illusive image. I attempted a popular lecture on this topic, but found it difficult to interest an audience in a matter requiring so much previous optical knowledge. In the spring 
of 1846 I communicated the leading principles of what I thought then questionable discoveries, either to Prof, Bache or to Prof. Henry, and consulted him as to their originality. He gave his opinion that they were new. Without the least disposition to contest the point of originality, which I have failed to establish by neglecting to publish my results, I wish merely to inform $m y$ friends of what $I$ have in fact done, and thus appear as a collateral witness to the truth and interest of Sir David Brewster's paper. He has bronght forward some points which had never presented themselves to me. That figures less distant than the two eyes may be so viewed as to form an illusive image at a greater distance than the object itself, is evidently true, yet I had never made or anticipated the experiment. Two such small figures might occupy such a situation as to form the pictures on the retina due to a single larger object placed at a greater distance, and thus become an optical equivalent to that object. I am now experimenting on the subject of single vision produced by two identical figures of different colours. So far the results have not excited any very surprising interest. The illusive image, as would be anticipated, usually exhibits the effect of a commingling of the colours; but by directing the attention to one or the other eye, one or the other colour may be made to predominate. Thus a cameleon picture is formed, changing colour at the will of the inspector.

Sir David Brewster alludes in his paper to some discoveries made by Prof. Wheatstone, in reference to "binocular" vision of objects of three dimensions. I have not seen the paper on that subject, nor had I turned my attention in the least to its consideration ; yet so intimately is it connected with the principles just laid down, that upon its being named certain important conclusions at once present themselves. Thus when the hand is held edgewise, within three inches of the nose, one eye will receive an image of the palm and the other of the opposite side; and the two pictures, being dissimilar, cannot fall on corresponding parts of the retina and produce a single perfect image. Let any one make the experiment, and he will perceive that Hogarth's caricature of bad perspective, in the figure of a barrel with both ends visible at the same time, was not altogether absurd; for if the barrel be shorter than the distance between the eyes, it is practicable. The same thing will occur with regard to any solid, as a cube, which has several aspects, and the imperfection will be evidently greater as the object is smaller and nearer the eye.

The experiments on this interesting subject can be extended and varied in many ways highly interesting and instructive; 
and as no other apparatus is required than our eyes and the objects of our inspection, it would seem that they were ensily made. But it requires rather an acquired power over the organs of vision to be readily successful. Sir David Brewster applied "binocular" convergence upon two figures, drawn side by side to superimpose one upon the other, and compare their exactness in point of size and form. I have extended the same operation to figures of unequal size, though of the same form. My son had just completed a half-size copy of a drawing representing an Arab on horseback, the correctness of which had been questioned. It was evident that, being placed at distances proportionate to their size, the images of the original and copy on the retina would be equal when a consistent illusive image might be obtained by convergence. The original was hung on the wall, and the half-size copy suspended at about half the distance from the observer, at such an angle that one could be fully seen beside the other. I converged or superimposed the images, and found them so nearly to coincide, that the common ontline was merely elegantly softened by the inequalities. In this experiment it appeared as if the eye, when the figures did not exactly coincide, had some power to complete the work or conceal the imperfections.

I have just succeeded in substituting a blank tablet for one of the pictures, and in tracing upon it with a pencil the illusive inage converged from the other tablet. But this is not a very practicable method of copying pictures, requiring unusual command and steadiness of the optical axes for even the most moderate success in the operation.

XXVI. Analytical Proof of the Parallelogram of Forces. By T. H. PratT.

To the Editors of the Philosophical Magazine and Journal. Genthemen,

N my work on Mechanical Philosophy, I have given a proof of the Parallelogram of Forces which depends on the solution of the following functional equation,

$$
\{f(\theta)\}^{2}+\left\{f\left(\frac{\pi}{2}-\theta\right)\right\}^{2}=1 . \quad . \quad . \quad .
$$

I there solved this equation indirectly. The following direct solution may be acceptable to some of your readers.

Put

$$
\{f(\theta)\}^{2}=\cos ^{2} \theta+(\cos \theta-\sin \theta) \phi(\theta)
$$

